TITLE:

HOW DO JAPANESE PERCEIVE INDIVIDUALISM? EXAMINATION OF THE MEANING OF INDIVIDUALISM IN JAPAN

$\operatorname{AUTHOR}(\mathrm{S}):$

OGIHARA, Yuji; UCHIDA, Yukiko; Kusumi, Takashi

CITATION:

OGIHARA, Yuji ...[et al]. HOW DO JAPANESE PERCEIVE INDIVIDUALISM? EXAMINATION OF THE MEANING OF INDIVIDUALISM IN JAPAN. Psychologia 2014, 57(3): 213-223

ISSUE DATE:

2014

URL:

http://hdl.handle.net/2433/198302

RIGHT:

The copyright for articles published in the journal is held by the Psychologia Society.; 発行者の許可を得て登録しています. 


\title{
HOW DO JAPANESE PERCEIVE INDIVIDUALISM? EXAMINATION OF THE MEANING OF INDIVIDUALISM IN JAPAN
}

\author{
Yuji OGIHARA ${ }^{1)}$, Yukiko UCHIDA ${ }^{2)}$, and Takashi KUSUMI') \\ ${ }^{1)}$ Department of Cognitive Psychology in Education, Graduate School of Education, \\ Kyoto University, Japan \\ ${ }^{2)}$ Kokoro Research Center, Kyoto University, Japan
}

\begin{abstract}
It has been suggested that individualistic systems have been recently employed in Japan, and Japanese people have become more individualistic. However, previous research suggested that such cultural changes have negative associations with interpersonal relationships and happiness for Japanese (Ogihara \& Uchida, 2014). In the present research, to demonstrate a negative aspect of individualism in Japan, we examined the meaning of individualism which Japanese people hold. Japanese participants aged 16 to 69 reported their evaluation to the word "individualism" and their perception of an "individualistic person." We found that individualism was regarded as being neutral and ambivalent, including both the positive aspect of being "with independence and freedom" and the negative aspect of being "without positive interpersonal relationships." In contrast, participants predicted others' evaluation of individualism to be more negative than their own evaluation, since they presumed that others would not consider the positive aspect of independence and freedom.
\end{abstract}

Key words: individualism, meaning, independence, interpersonal relationships, discrepancy between own attitude and predicted others' attitude

\section{INTRODUCTION}

\section{Individualization of Japanese Society}

The spread of globalization has been unstoppable. People, money, goods and information have become increasingly mobile across the world. Rapid transportation technology, the liberalization of international trade, and new forms of media such as social networking service have contributed to the emergence of a more global environment.

Due to the progress of globalization, more and more European-American values and systems have flowed into Japanese society, causing the systems and environments in Japan to become more individualistic. In this paper, we define individualism as "a social pattern that consists of loosely linked individuals who view themselves as independent of collectives (Triandis, 1995, p. 2)." Examples of such patterns can be seen in the pay-per

Yuji Ogihara received financial support for the research from Suntory Foundation. We thank Kosuke Takemura for his helpful comments on our research. We are also thankful to Laura Froehlich and Pamela Taylor for their feedback on the manuscript.

Corresponding concerning this article should be addressed to Yuji Ogihara, Department of Cognitive Psychology in Education, Graduate School of Education, Kyoto University, Yoshida-honmachi, Sakyo-ku, Kyoto 606-8501, Japan (e-mail: ogihara.yuuji.56u@st.kyoto-u.ac.jp). 
performance system which evaluate employees based on their personal achievement instead of their age or length of service (i.e., seniority system) in companies (e.g., Jo, 2004; Takahashi, 2010), and the emphasis on independence and uniqueness in the field of education (e.g., Doi, 2004).

Due to changes towards an individualistic model in Japanese systems and environments, it has been suggested that Japanese psychological tendencies and behaviors have also become more individualistic. For example, family size has decreased, the divorce rate has increased and independence in child socialization has become increasingly prioritized $^{1}$ (Hamamura, 2012). Moreover, Ogihara et al. (2014) showed that parents in Japan have given more unique names to their babies recently, indicating the increase in uniqueness and individualism.

\section{Positive Aspects of Individualism in Japan}

Individualization in Japan is thought to have occurred primarily within the domain of economics. For example, Japanese companies have implemented European-American systems and values in order to foster the international trade of services and products all over the world. Due to the removal of regulations and the increase of multinational companies, this trend has continued. Under individualization, people who are independent from others and seek personal achievement are thought to be adaptive.

The positive effects of individualism are not limited to economic situations, but are also found in other contexts. Individualism provides people the freedom of choice (Triandis, 1995) and disengages them from the constraints of a collectivistic society (e.g., Yamagishi \& Yamagishi, 1994).

\section{Negative Aspects of Individualism in Japan}

However, previous research suggested that individualization in Japan might have a negative relation to psychological aspects such as interpersonal relationships and wellbeing. Ogihara and Uchida (2014) conducted a survey with undergraduate students in Japan and the U.S., and found that people with high individualistic tendency had fewer close friends and felt lower subjective well-being only in Japan, but not in the U.S. In addition, they indicated that even within a Japanese company which introduced individualistic systems (e.g., each individual is valued in accordance with their personal work performance, employees' personal achievement is explicitly displayed in the workplace), the same pattern of results was found.

Why are such negative relationships between individualism and interpersonal relationships and subjective well-being found only in Japanese cultural context? We assume that one of the reasons is that individualism is not historically established in Japan, and it conflicts with traditional norms and values. In European-American cultures, individualistic values and systems have been fostered and maintained over a long period of

\footnotetext{
${ }^{1}$ It should be noted that some indices did not show the increase of individualism in Japan (Hamamura, 2012). All the indices that did not show the increase in individualistic tendency were self-report items of beliefs and values. However, behavioral measures consistently suggested the increase in individualism in Japan such as family size and divorce rate (see, Ogihara et al., 2014; Ogihara \& Uchida, 2014).
} 
time. For example, herder lifestyle in relatively large areas (e.g., Uskul, Kitayama, \& Nisbett, 2008), the Protestant prioritization of each believer's personal relationship with God over a communal relationship mediated by church authorities and collective worship in a church (e.g., Weber, 1920), low pathogen prevalence in the past (e.g., Fincher, Thornhill, Murray, \& Schaller, 2008), voluntary settlement by those who were originally more independent and the need to live independently across a wide area of land (e.g., Kitayama, Ishii, Imada, Takemura, \& Ramaswamy, 2006) produced and maintained individualistic values and systems. In contrast, Japanese culture has not been traditionally individualistic (Hofstede, 1980; Markus \& Kitayama, 1991, 2010; Triandis, 1995). For example, agricultural lifestyle in a comparatively small area (e.g., Uskul et al., 2008); Confucian and Buddhist ideas, as well as the concept of yin-yang, which permit contradiction (e.g., Nisbett, 2003); and high pathogen prevalence in the past (e.g., Fincher et al., 2008) have all contributed to the construction and maintenance of collectivistic values and systems. Although drastic changes have recently occurred due to globalization, collectivistic norms and values still remain in Japan. Therefore, individualization in Japan might produce a conflict between the new ideas of individualism and traditional norms and values. In such a conflict, individualism and traditional cultural values do not coexist in harmony, and people who would like to be more individualistic are more likely to distance themselves from traditional interpersonal relationships.

In addition, individualistic people in Japan might not have the appropriate psychological tendencies or behaviors which are supposed to be necessary in an individualistic culture (Ogihara \& Uchida, 2014). Indeed, people in an individualistic culture actively construct and maintain interpersonal relationships. For example, European Americans explicitly seek social support more than Asians (Kim, Sherman, Ko, \& Taylor., 2006) and are active in seeking new interpersonal relationships (Oishi et al., 2013). However, Japanese with high individualistic tendency might not apply such interpersonal strategies. As a result, an individualistic Japanese person would not have adequate positive interpersonal relationships and would consequently experience lower subjective well-being.

\section{Discrepancy between Own Attitude and Prediction of Others 'Attitude towards Individualism}

Regarding cultural changes and how such changes affect psychological tendencies and behaviors, it is important to measure not only people's own attitudes but also their beliefs about or prediction of the attitudes of others (e.g., Nisbett \& Cohen, 1996). People try to change their own values or attitudes in accordance with cultural changes. However, cultural change does not proceed uniformly across different places or at different times, so standards of behavior or predictions of behavior are likely to be vague and unclear. Thus, people predict that others around them might not change their values or attitudes, causing them to hesitate to change their own behavior (e.g., Hashimoto, 2011). Thus, a discrepancy between their own attitudes and their prediction of others' attitudes arises (e.g., Miller \& Prentice, 1994).

To be more specific to this kind of discrepancy between own attitude and prediction of others' attitude, it has been demonstrated that in Japan people assume that others in 
general are more collectivistic than themselves (Hashimoto, 2011). Due to the influence of individualization of the systems or environments, Japanese people have come to hold individualistic attitudes or beliefs (even though it sometimes brings negative consequences) but they might assume that others in general have more collectivistic attitudes or beliefs.

\section{Present Study}

The purpose of this study is to examine the characteristics of individualism in Japan by assessing the meaning of individualism held by Japanese people. Individualism in Japan has predominantly been employed due to the requirements of the global marketplace because individualism can promote independence and personal achievement. Moreover, it has been considered that individualism brings freedom of choice (Triandis, 1995) and can free Japanese people from collectivism-based social constraints. Hence, we expect that individualism to be regarded as "independence and freedom" (Hypothesis 1).

On the other hand, if individualism has a negative effect on interpersonal relationships in Japan as demonstrated by Ogihara and Uchida (2014), the meaning of individualism should reflect the negative connotations in the domain of relationships. Therefore, individualism would also be perceived as a "lack of positive interpersonal relationships" (Hypothesis 2).

In addition, according to previous research showing that Japanese assume that others in general are less individualistic and more collectivistic compared to themselves (Hashimoto, 2011), people would predict that others have more negative attitudes towards individualism than they hold themselves (Hypothesis 3).

In this study, we analyzed the meaning of the word "individualism" as a general evaluation, and the meaning of an "individualistic person" as a specific evaluation.

\section{METHOD}

\section{Participants}

A total of 997 Japanese people participated in an individual web survey. The participants were recruited from a large internet survey company. A broad range of people answered the questionnaire consistent with the actual ratios of sex and age in Japan (Male: 499, Female: 498; $M_{\text {age }}=43.24, S D_{\text {age }}=14.85,16-69$ age; 10s: 76 , 20s: 152, 30s: 199, 40s: 185, 50s: 182, 60s: 203). The survey was conducted in March 2013.

\section{Measures}

Evaluation of the word "individualism" We measured an inclusive evaluation of individualism in two ways. One item measured the participant's evaluation of individualism by asking "What do you think about the word 'individualism,2 (in Japanese 個人主義, Kojinshugi)?” The other item measured the participants' prediction of other people's evaluation of individualism by asking "What do you think others in general think about the word 'individualism'?" Participants responded to these two items by using a 7-point scale ( -3 : very negative, 0 : neutral, 3 : very positive).

Evaluation of an individualistic person We measured the evaluation of an individualistic person using a semantic differential method. Participants reported the extent to which each term in a word pair applied to their meaning of an individualistic person (e.g., "independent - dependent", "selfish - thoughtful," "likely to

\footnotetext{
${ }^{2}$ In this questionnaire, we deliberately did not define "individualism" because we thought it is important to examine the lay perception of individualism which people hold, not the meaning defined by scientists.
} 
be helped by surrounding people - unlikely to be helped by surrounding people"; see Fig. 1 for contents of all items) using a 7-point scale (1: very, 2: quite, 3: somewhat, 4: neither, 5: somewhat, 6: quite, 7: very). Most items were employed by Hashimoto (2011) and Inoue and Kobayashi (1985), while others were developed independently for this study. Items were presented in counterbalanced order.

\section{RESULTS}

\section{Evaluation of the Word "Individualism"}

To examine how Japanese evaluate individualism, we conducted a three-way ANOVA with perspective as a within-subject factor (self-evaluation, prediction of others' evaluation, 0 in order to check whether the ratings of the evaluation were above 0 or not), and age (10s, $20 \mathrm{~s}, 30 \mathrm{~s}, 40 \mathrm{~s}, 50 \mathrm{~s}, 60 \mathrm{~s}$ ) and sex (male, female) as between-subject factors. We found a significant main effect for perspective, $F(1.98,1951.84)=51.29, p<.001, \eta_{\mathrm{p}}{ }^{2}=.05$. Multiple comparisons showed that self-image $(M=.00, S D=1.30)$ was not different from $0(p=1.00)$ but the prediction of others' image $(M=-.39, S D=1.22)$ was significantly lower than $0(p<.001)$, with a significant difference from scores of self-evaluation $(p<.001)$. There were no main effects for age, $F(5,985)=.77, p=.57, \eta_{\mathrm{p}}{ }^{2}=.00$, or sex, $F(1,985)=.12, p=.73, \eta_{\mathrm{p}}{ }^{2}=.00$. Also, there was no three-way interaction of perspective, age and sex, $F(9.91,1951.84)=.47, p=.91, \eta_{\mathrm{p}}{ }^{2}=.00$, two-way interaction of perspective and age, $F(9.91,1951.84)=1.12, p=.34, \eta_{\mathrm{p}}{ }^{2}=.01$, two-way interaction of perspective and sex, $F(1.98,1951.84)=.92, p=.40, \eta_{\mathrm{p}}{ }^{2}=.00$, or two-way interaction of age and sex, $F(5,985)=.64, p=.67, \eta_{\mathrm{p}}{ }^{2}=.00$. Hence, it was shown that participants themselves had a neutral evaluation of the word "individualism" but predicted that others in general have a negative evaluation of the word "individualism."

\section{Evaluation of an Individualistic Person}

Mean scores and standard errors are shown in Fig. 1. On one hand, participants regarded an individualistic person in terms of positive traits such as "independent," "strong" and "free." On the other hand, participants also perceived an individualistic person in negative terms such as being "unlikely to be helped by surrounding people," "selfish" and "cold."

To verify that Japanese people tend to have two kinds of meanings of an individualistic person (i.e., an "independent and free person" and a "person who do not have positive relationships with others"), we conducted an exploratory factor analysis (maximum likelihood solution, promax rotation). With the criteria over an eigenvalue 1 , we found the predicted two factors (Table 1). The first factor was named the "relationship factor" because the factor loadings of items such as "easy to be familiar with-difficult to be familiar with," "warm - cold," "likely to be helped by surrounding people - unlikely to be helped by surrounding people" were high on this first factor. The second factor was named "independence factor" because the factor loadings of items such as "independentdependent," "strong - weak," "free - unfree" were high on this second factor'.

\footnotetext{
${ }^{3}$ This result was also found when we conducted factor analyses separately for each age category.
} 

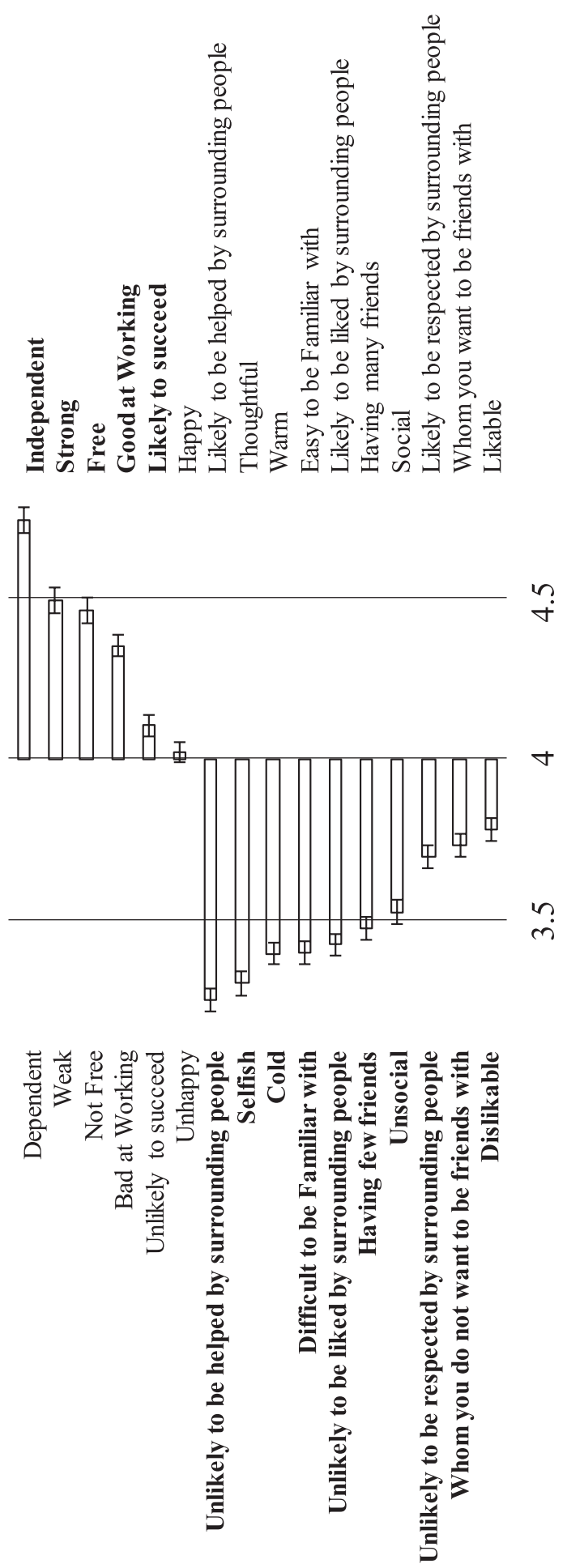
Table 1. Result of factor analysis (maximum likelihood solution, promax rotation)

\begin{tabular}{|c|c|c|c|}
\hline & $\begin{array}{c}\text { Relationship } \\
\text { Factor } \\
(\alpha=.92)\end{array}$ & $\begin{array}{c}\text { Independence } \\
\text { Factor } \\
(\alpha=.83)\end{array}$ & Communality \\
\hline Easy to be familiar with - Difficult to be familiar with & .84 & -.08 & .65 \\
\hline Warm - Cold & .82 & -.10 & .61 \\
\hline $\begin{array}{l}\text { Likely to be helped by surrounding people - } \\
\text { Unlikely to be helped by surrounding people }\end{array}$ & .79 & -.16 & .54 \\
\hline $\begin{array}{l}\text { Likely to be liked by surrounding people - } \\
\text { Unlikely to be liked by surrounding people }\end{array}$ & .79 & -.09 & .57 \\
\hline Thoughtful - Selfish & .78 & -.16 & .53 \\
\hline Having many friends - Having few friends & .71 & .03 & .53 \\
\hline $\begin{array}{l}\text { Whom you want to be friends with - } \\
\text { Whom you do not want to be friends with }\end{array}$ & .67 & .17 & .58 \\
\hline Likable - Dislikable & .60 & .24 & .54 \\
\hline Social - Unsocial & .59 & .12 & .42 \\
\hline $\begin{array}{l}\text { Likely to be respected by surrounding people - } \\
\text { Unlikely to be respected by surrounding people }\end{array}$ & .58 & .25 & .52 \\
\hline Independent - Dependent & -.23 & .81 & .55 \\
\hline Strong - Weak & -.10 & .78 & .55 \\
\hline Free - Not free & -.01 & .71 & .50 \\
\hline Good at working - Bad at working & .03 & .68 & .49 \\
\hline Likely to succeed - Unlikely to succeed & .15 & .51 & .35 \\
\hline Happy - Unhappy & .38 & .45 & .48 \\
\hline
\end{tabular}

Note. Boldface indicates highest factor loadings. Inter-factor correlations .42

Relationship between the Evaluation of the Word "Individualism" and the Evaluation of an Individualistic Person

In order to examine the difference in people's evaluation of individualism and their prediction of others' evaluation, we investigated the relationships between the valence of individualism (evaluation of the word "individualism") and the specific evaluation of individualism (evaluation of an individualistic person). We calculated the correlations between the participants' evaluation of the word "individualism," participants' prediction 
Table 2. Correlation coefficients between participants' own evaluation, prediction of others' evaluation, independent evaluation mean score and relationship evaluation means score

\begin{tabular}{lcc}
\hline & $\begin{array}{c}\text { Independent evaluation } \\
\text { mean score }\end{array}$ & $\begin{array}{c}\text { Relationship evaluation } \\
\text { mean score }\end{array}$ \\
\hline Participants' own evaluation &. $\mathbf{. 0}_{\mathrm{a}}^{* * *}$ & $\mathbf{. 2 4}_{\mathrm{a}}{ }^{* * *}$ \\
Prediction of others' evaluation & $.00_{\mathrm{b}}$ & $\mathbf{. 1 3}_{\mathrm{c}}{ }^{* * *}$ \\
\hline
\end{tabular}

Note. Correlation coefficients not sharing the same subscripts are significantly different. $* * * p<.001, N=997$

of others" evaluation of the word "individualism," the mean score of items which have high loadings in independence factor in the evaluation of an individualistic person, and the mean score of items which have high loadings in relationship factor in the evaluation of an individualistic person (Table 2).

Participants' evaluation of the word was positively correlated both with the independent evaluation of an individualistic person and the relationship evaluation of individualistic person. There was no difference between the correlation scores, $t(997)=1.20, p=.23$. This means that "being independent" and "having positive interpersonal relationships" were positively and equally associated with the general evaluation of individualism, showing that people understand both "being independent" and "having positive interpersonal relationships" are important and good to almost the same degree. People understand that individualism has positive aspects because it provides independence and freedom, but also perceive individualism to be negative because it deteriorates close interpersonal relationships at the same time, which might lead to the overall neutral evaluation of individualism.

In contrast, the prediction of others' evaluation of individualism was positively correlated only with the relationship evaluation of an individualistic person, but was not correlated with the independent evaluation of an individualistic person. There was a significant difference between these two correlations, $t(997)=3.81, p<.001$. That is, the prediction of others' evaluation depended more on the extent of an individualistic person having positive interpersonal relationships than on the extent of an individualistic person being independent. In other words, people assume that others in general might value "having positive interpersonal relationships" but do not value "being independent."

Both the independent evaluation and the relationship evaluation for an individualistic person were more strongly correlated with participants' own evaluation of individualism than with participants' predictions of others' evaluation, $t(997)=6.17,3.40$, ps $<.001$. This result was expected because independent evaluation and relationship evaluation are participants' own evaluation, which should correlate with participants' general evaluation toward individualism. 


\section{DISCUSSION}

In the present study, we investigated the meaning of individualism in Japan. Japanese society, which was not traditionally individualistic (Hofstede, 1980; Markus \& Kitayama, 1991, 2010; Triandis, 1995), has become more individualistic (Hamamura, 2012; Ogihara et al., 2014). But if this individualistic tendency is negatively associated with positive interpersonal relationships in Japan, then the negative impact of individualism would be reflected in the meaning of individualism. Moreover, given that Japanese predict that others in general are more collectivistic than themselves, the negativity of individualism would be greater in the prediction of others' attitudes.

\section{Meaning of Individualism}

Individualism was generally regarded neutrally in Japan. This neutral attitude toward individualism was consistent across age groups and sexes, which suggests that the phenomenon is common across Japanese society.

Specifically, consistent with Hypothesis 1, an individualistic person was perceived as an "independent," "strong," and "free" individual, and this evaluation was positively related to the valence of the word "individualism." Therefore, individualism is positively regarded in a context where it facilitates independence and personal achievement. It has been indicated that individualism has a positive aspect of providing effective values or systems in a free, highly mobile, and competitive market (Triandis, 1995). In addition, it has also been indicated that individualism can free people from the constraints of a traditionally collectivistic society (e.g., Yamagishi \& Yamagishi, 1994).

In contrast, consistent with Hypothesis 2, an individualistic person was regarded as "unlikely to be helped by surrounding people," "selfish," and "cold." Also, this evaluation was negatively correlated with the general evaluation of individualism. Thus, consistent with Ogihara and Uchida (2014), Japanese participants' meaning of individualism was associated with a deterioration of positive interpersonal relationships based on their experience of the consequences of acting in an individualistic way or observing others act in an individualistic way.

Taken together, individualism, at least in present-day Japan, is regarded ambivalently, including both positive and negative aspects, which means that individualism promotes independence but dampens interpersonal relationships. Few research investigated the negative influence of individualism in East Asian cultures (e.g., Ogihara \& Uchida, 2014). Hence, present study contributes to an understanding of how individualism acts on psychology and behavior in East Asian cultural context.

\section{Discrepancy between People's own Attitude and Prediction of Others'Attitudes for Individualism}

As discussed earlier, it has been shown that Japanese have a neutral attitude towards individualism. However, consistent with Hypothesis 3, people assumed that others in general would have a more negative attitude towards individualism than they hold themselves. In line with Hashimoto (2011), it is possible that the Japanese have accepted 
individualism due to societal changes, but that they still predict that other Japanese people in general do not accept individualism.

Furthermore, the evaluation of an individualistic person as not having positive interpersonal relationships was negatively associated with both their own and their prediction of others' evaluation of individualism. Yet, the evaluation of an individualistic person as being independent is associated positively only with their own evaluation of individualism, but not with their prediction of other people's evaluation of individualism. It is likely that Japanese people predicted that others in general regard individualism as negative because they assumed that others in Japanese society stress having positive interpersonal relationships over being independent.

\section{Limitations and Future Research}

In this study, we focused on the meaning of individualism in Japan, and found that Japanese perceive individualism to be ambivalent. We did not examine the meaning of individualism in European-American cultural context, where we expect that individualism is perceived positively, therefore it is not clear whether this ambivalent perception is unique in Japan. Future research should investigate this question in cross-cultural studies.

Although we examined the meaning of "individualism" in the present research and suggested the two-sidedness of individualism, the results might be caused by Japanese dialectic cognitive tendency (i.e., Japanese might evaluate everything ambivalently). Previous research showed that people in East Asia tend to perceive objects holistically and accept both positive and negative aspects simultaneously without contradiction (dialectic cognitive tendency; e.g., Bagozzi, Wong, \& Yi, 1999). However, our findings were not limited to the valence, and what we believe to be more important is the concrete meaning of individualism. Specifically, Japanese have a positive connotation that individualism is independence and freedom, but also have a negative connotation that individualism includes deteriorating positive interpersonal relationships. This finding goes beyond valence and provides a deeper understanding of individualism in Japan.

The present research supported the finding that individualism in Japan is associated with a deterioration of positive interpersonal relationships, but it is unclear how this happens. Future research is needed to discover the process, which could prevent and ameliorate social issues caused by the deterioration of positive interpersonal relationships.

\section{REFERENCES}

Bagozzi, R. P., Wong, N., \& Yi, Y. 1999. The role of culture and gender in the relationship between positive and negative affect. Cognition and Emotion, 13, 641-672.

Doi, T. 2004. Kosei wo aorareru kodomotachi [Children who are abetted to have uniqueness]. Tokyo: Iwanami Shoten. (In Japanese).

Fincher, C. L., Thornhill, R., Murray, D. R., \& Schaller, M. 2008. Pathogen prevalence predicts human crosscultural variability in individualism/collectivism. Proceedings of the Royal Society: Biological Sciences, 275, 1279-1285.

Hamamura, T. 2012. Are cultures becoming individualistic? A cross-temporal comparison of individualismcollectivism in the United States and Japan. Personality and Social Psychological Review, 16, 3-24. 
Hashimoto, H. 2011. Interdependence as a self-sustaining set of beliefs. Japanese Journal of Experimental Social Psychology, 50, 182-193. (In Japanese with English abstract)

Hofstede, G. 1980. Culture's consequences: International differences in work-related values. Beverly Hills, CA: Sage.

Inoue, M., \& Kobayashi, T. 1985. The research domain and scale construction of adjective-pairs in a semantic differential method in Japan. Japanese Journal of Educational Psychology, 33, 253-260. (In Japanese with English abstract)

Jo, S. 2004. Uchigawa kara mita FUJITSU [The inside of FUJITSU]. Tokyo: Kobunsha. (In Japanese)

Kim, H. S., Sherman, D. K., Ko, D., \& Taylor, S. E. 2006. Pursuit of comfort and pursuit of harmony: Culture, relationships, and social support seeking. Personality and Social Psychology Bulletin, 32, 1595-1607.

Kitayama, S., Ishii, K., Imada, T., Takemura, K., \& Ramaswamy, J. 2006. Voluntary settlement and the spirit of independence: Evidence from Japan's "northern frontier." Journal of Personality and Social Psychology, 91, 369-384.

Markus, H. R., \& Kitayama, S. 1991. Culture and the self: Implications for cognition, emotion, and motivation. Psychological Review, 98, 224-253.

Markus, H. R., \& Kitayama, S. 2010. Cultures and selves: A cycle of mutual constitution. Perspectives on Psychological Science, 5, 420-430.

Miller, D. T., \& Prentice, D. A. 1994. Collective errors and errors about the collective. Personality and Social Psychology Bulletin, 20, 541-550.

Nisbett, R. E. 2003. The geography of thought: How Asians and Westerners think differently ... and why. New York: Free Press.

Nisbett, R. E., \& Cohen, D. 1996. Culture of honor: The psychology of violence in the South. Boulder, CO: Westview Press.

Ogihara,Y., Fujita, H., Tominaga, H., Ishigaki, S., Kashimoto, T., Takahashi, A., et al. 2014. Are unique names increasing? Rise in uniqueness and individualism in Japan. Manuscript submitted for publication.

Ogihara, Y., \& Uchida., Y. 2014. Does individualism bring happiness? Negative effects of individualism on interpersonal relationships and happiness. Frontiers in Psychology, 5: 135.

Oishi, S., Kesebir, S., Miao, F. F., Talhelm, T., Endo, Y., Uchida, Y., et al. 2013. Residential mobility increases motivation to expand social network: But why? Journal of Experimental Social Psychology, 49, 217 223.

Takahashi, N. 2010. Kyomou no seikashugi: Nihongata nenko sei fukkatsu no susume [Fallacy of Pay-perperformance system in Japan: Recommendation of seniority criterion system]. Tokyo: Chikumashobo. (In Japanese)

Triandis, H. C. 1995. Individualism \& collectivism. Boulder, CO: Westview Press.

Uskul, A. K., Kitayama, S., \& Nisbett, R. E. 2008. Ecocultural basis of cognition: Farmers and fishermen are more holistic than herders. Proceedings of the National Academy of Sciences of the United States of America, 105, 8552-8556.

Weber, M. 1920. Die protestantische ethik und der Geist des Kapitalismus. Gesammelte Aufsätze zur Religionssoziologie, I (S. 1-206). Tübingen, Germany: J. C. B. Mohr.

Yamagishi, T., \& Yamagishi, M. 1994. Trust and commitment in the United States and Japan. Motivation and Emotion, 18, 129-166.

(Manuscript received 21 April, 2014; Revision accepted 15 October, 2014) 